\title{
Commentary: Pump exchange: Harmful waste or wise investment?
}

Ronald K. Woods, MD, PhD, ${ }^{\text {a }}$ Iki Adachi, MD, ${ }^{\mathrm{b}}$ and David L. S. Morales, MD $^{\mathrm{c}}$

We congratulate Salerno and colleagues ${ }^{1}$ for a timely and excellent expert review of exchanging a left ventricular assist device from an HVAD (Medtronic, Inc) to a HeartMate 3 (Abbott Labs). Even the surgeon experienced in left ventricular assist devices will appreciate the authors' considerate technical insights and recommendations. We understand the basis of recommending only "for-cause" conversion, at least for now, based on the available data. The data were provided by Cogswell and colleagues, ${ }^{2}$ who evaluated the most recent 4-year interval of the Society of Thoracic Surgeons Intermacs database. Based on a cohort of 45 patients undergoing pump exchange (3797 HVAD implants during this time interval) and using parametric model estimates of survival, they reported that 1-month survival after exchange was $79.4 \%$ compared with $83.8 \%$ if remaining on HVAD support; and 6-month survival after exchange was $73.6 \%$ compared to $79 \%$ if remaining on HVAD support. The authors appropriately acknowledged lack of data regarding issues driving the decision to exchange as well as the physiologic status at the time of exchange. We emphasize one other study-Cho

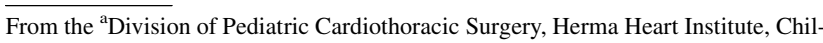
dren's Wisconsin, Milwaukee, Wis; ' ${ }^{\text {} M i c h a e l ~ E . ~ D e B a k e y ~ D e p a r t m e n t ~ o f ~ S u r g e r y, ~}$ Congenital Heart Surgery, Texas Children's Hospital, Baylor College of Medicine, Houston, Tex; and 'Heart Institute, Cincinnati Children's Hospital Medical Center, Cincinnati, Ohio.

Disclosures: Dr Woods reported cofounder of OperVu, Inc. Dr Adachi reported consultant or proctor for Berlin Heart Inc, Medtronic Inc, Jarvik Inc, BiVACOR Inc, and Abbott, Inc. Dr Morales reported consultant for Berlin Heart, Inc; proctor, consultant, and member of medical advisory board for SynCardia Systems, LLC; consultant and instructor for Abbott Medical, Inc (Thoratec Division); and consultant, investigator, and member of medical advisory board for Azyio Inc, Xeltis Inc, and Peca Labs.

The Journal policy requires editors and reviewers to disclose conflicts of interest and to decline handling or reviewing manuscripts for which they may have a conflict of interest. The editors and reviewers of this article have no conflicts of interest.

Received for publication Nov 19, 2021; revisions received Nov 19, 2021; accepted for publication Nov 19, 2021; available ahead of print Nov 25, 2021.

Address for reprints: Ronald K. Woods, MD, PhD, Division of Pediatric Cardiothoracic Surgery, Children's Wisconsin, 9000 W Wisconsin Ave, MS B 730, Milwaukee, WI 53226 (E-mail: rwoods@chw.org).

J Thorac Cardiovasc Surg 2022;163:2128-9

$0022-5223 / \$ 36.00$

Copyright (c) 2021 by The American Association for Thoracic Surgery

https://doi.org/10.1016/j.jtcvs.2021.11.048

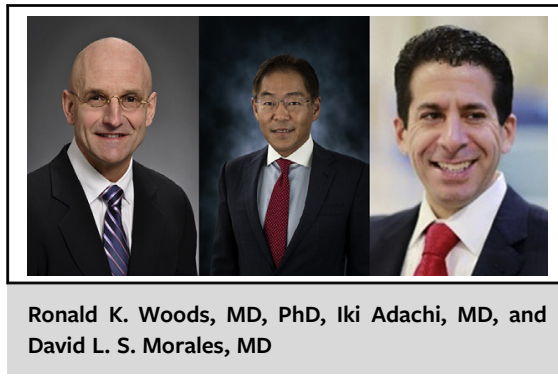

CENTRAL MESSAGE

Until further data are available, individualized assessment and best judgment should govern decisions about pump conversion in pediatric and adult congenital patients.

and colleagues ${ }^{3}$ recently reported a much greater late hazard phase risk of stroke with HVAD (compared with HeartMate 3, more than 3000 patients in each group).

The removal of HVAD from the market has posed challenges for us in the pediatric and congenital community in how we manage our smaller patients-determining lower limits for patient size, modifications of implantation technique, etc. Now, we must navigate a new unknown on which the expert authors have provided clear guidance for the adult community. In our community, we implant far fewer pumps in a more anatomically diverse group of patients and only have a small cohort of HVAD patients currently on support (although not necessarily representative, the 3 of us have only 9 patients currently on HVAD). We also have no data on conversion, only recent data for each device. Auerbach and colleagues ${ }^{4}$ reported a cohort of 50 patients with an HVAD (from the Advanced Cardiac Therapies Improving Outcomes Network-ACTION) in which stroke occurred in only 4\% (although median time on support was only 71 days). For HeartMate 3, O'Connor and colleagues ${ }^{5}$ reported zero stroke or pump thrombosis in a cohort of 35 patients (from ACTION) with a median support time of 78 days. Survival was greater than $95 \%$ in both cohorts. Despite improving stroke rates in the pediatric community, we acknowledge the concerning longer-term adult HVAD data. Therefore, on the issue of conversion, we recommend doing what we do for most complex issues-carefully evaluate, try to be creative, do the risk/benefit analysis to the extent possible, and 
individualize care. At present, we would not adhere strictly to a "for-cause" basis (as defined by the authors) for conversion, particularly for a near adult-sized stable patient with destination therapy. However, we need more data and will continue to scrutinize the data as they become available and adjust our viewpoint accordingly.

\section{References}

1. Salerno CT, Hayward C, Hall S, Goldstein D, Saeed D, Schmitto J, et al. HVAD to HeartMate 3 left ventricular assist device exchange: best practices recommendations. J Thorac Cardiovasc Surg. 2022;163:2120-7.e5.
2. Cogswell R, Cantor RS, Vorovich E, Kilic A, Stehlik J, Cowger JA, et al. HVAD to HeartMate 3 device exchange: a Society of Thoracic Surgeons Intermacs analysis. Ann Thorac Surg. October 19, 2021 [Epub ahead of print].

3. Cho SM, Mehaffey JH, Meyers SL, Cantor RS, Starling RC, Kirklin JK, et al. Cerebrovascular events with patients with centrifugal-flow left ventricular assist devices. Circulation. 2021;144:763-72.

4. Auerbach SR, Simpson KE, on behalf of the ACTION Learning Network Investigators. HVAD usage and outcomes in the current pediatric ventricular assist device field: an Advanced Cardiac Therapies Improve Outcomes Network (ACTION) analysis. ASAIO J. 2021;67:675-80.

5. O'Connor MJ, Lorts A, Davies RR, Fynn-Thompson F, Joong A, Maeda K, et al. Early experience with the HeartMate 3 continuous-flow ventricular assist device in pediatric patients and patients with congenital heart disease: a multicenter registry analysis. J Heart Lung Transplant. 2020;39:573-9.
See Article page 2120.

\section{Commentary: Guidance during uncertain times: Navigating the HeartWare HVAD recall}

\author{
Alexis Shafii, MD, ${ }^{\text {a,b }}$ Kenneth Liao, MD, PhD, ${ }^{\text {a,b }}$ and \\ Ravi K. Ghanta, MD ${ }^{\mathrm{a}, \mathrm{b}}$
}

Ventricular assist device (VAD) technology is an established and essential option for patients with end-stage heart failure. In June 2021, Medtronic recalled the HeartWare HVAD system because it is associated with a high incidence of stroke, as well as a risk of device malfunction, specifically delay or failure of the pump to restart. According to the US Food and Drug Administration, these malfunctions led to more than 100 complaints, 14 deaths, and 13 pump removals. ${ }^{1}$ This unfortunate outcome has left approximately 4000 patients worldwide in a vexing situation.

\footnotetext{
From the ${ }^{\mathrm{a} M i c h a e l}$ E. DeBakey Department of Surgery, Baylor College of Medicine; and ${ }^{\mathrm{b}}$ Department of Cardiovascular Surgery, Texas Heart Institute, Houston, Tex. Disclosures: Dr Shafii was the Institutional Principal Investigator for the HeartWare Destination Therapy study. All other authors reported no conflicts of interest.

The Journal policy requires editors and reviewers to disclose conflicts of interest and to decline handling or reviewing manuscripts for which they may have a conflict of interest. The editors and reviewers of this article have no conflicts of interest.

Received for publication Dec 2, 2021; revisions received Dec 2, 2021; accepted for publication Dec 2, 2021; available ahead of print Dec 7, 2021.

Address for reprints: Ravi K. Ghanta, MD, Michael E. DeBakey Department of Surgery, Baylor College of Medicine, One Baylor Plaza, MC-390, Houston, TX 77030 (E-mail: ravi.ghanta@bcm.edu).

J Thorac Cardiovasc Surg 2022;163:2129-30

$0022-5223 / \$ 36.00$

Copyright (c) 2021 by The American Association for Thoracic Surgery

https://doi.org/10.1016/j.jtcvs.2021.12.003
}

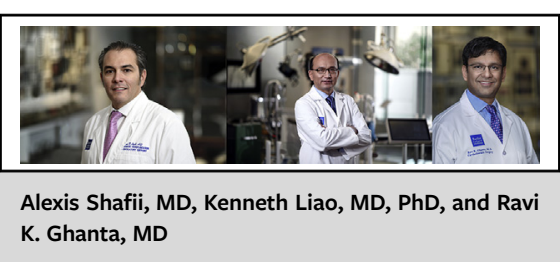

CENTRAL MESSAGE

HVAD to HeartMate 3 device exchange should only be performed "for cause" and in experienced centers. Prioritization for heart transplantation should be considered in HVAD patients.
For cardiac surgeons, the primary decisions are when and how these pumps should be replaced. Salerno and colleagues $^{2}$ present an Expert Opinion article on how to approach this question. The authors have a formidable cumulative experience in heart failure and mechanical circulatory support and represent a broad array of centers of excellence in the United States and Europe.

Given our experience at Baylor College of Medicine and Texas Heart Institute, we largely agree with the authors' principal points. First, patients currently supported by an HVAD should not undergo a prophylactic exchange to another device. Device failure rates are low $(\sim 0.4 \%)$, and an analysis of the Society of Thoracic Surgeons Intermacs registry associated HVAD-to-HM3 device exchange with $11 \%$ operative mortality and poorer 6-month survival compared with continued 